\title{
Avaliação da distribuição de cobre associado a compostos de diferentes massas moleculares na polpa de açaí
}

Samantha Leite da TRINDADE¹, Patrícia de Oliveira NUNES², Kelly das Graças FERNANDES³

\section{RESUMO}

Neste estudo, cromatografia de exclusão por tamanho (SEC) com detecção por UV e detecção off-line por espectrometria de absorção atômica em forno de grafite (GF AAS) foi usada para investigar a associaçáo de cobre a espécies de alta massa molecular (HMW) e baixa massa molecular (LMW) presentes na polpa de açaí (Euterpe oleracea Mart.). A concentração total de cobre obtida nos digeridos da polpa de açaí foi $10,5 \mu \mathrm{g} \mathrm{g}^{-1}$. Cobre foi encontrado associado às fraçóes de HMW e LMW, correspondentes às massas moleculares de 28,7, 2,6 e 0,43 kDa.

PALAVRAS-CHAVE: metal, SEC, GF AAS, proteínas, Euterpe oleracea Mart.

\section{Evaluation of the distribution of copper associated to compounds of different molecular weights in the acai pulp}

\section{ABSTRACT}

In this study, size exclusion chromatography (SEC) with ultraviolet (UV) and graphite furnace atomic absorption spectrometry (GF AAS) off-line detection was used to investigate the association of copper to high molecular weight (HMW) and low molecular weight (LMW) species present in Euterpe oleracea Mart. pulp. Total concentration of copper was $10.5 \mu \mathrm{g} \mathrm{g}^{-1}$. Copper was found to be associated to fractions corresponding to $28.7,2.6$ and $0.43 \mathrm{kDa}$.

KEYWORDS: metal, SEC, GF AAS, proteins, Euterpe oleracea Mart.

\footnotetext{
1 Programa de Pós-Graduação em Química, Instituto de Ciências Exatas e Naturais, Universidade Federal do Pará, 66075-110, Belém-PA, Brasil. E-mail: samanthaquimica@yahoo.com.br

2 Programa de Pós-Graduação em Química, Instituto de Ciências Exatas e Naturais, Universidade Federal do Pará, 66075-110, Belém-PA, Brasil. E-mail: patyoliveiranunes@hotmail.com

${ }^{3}$ Faculdade de Química, Instituto de Ciências Exatas e Naturais, Universidade Federal do Pará, 66075-110, Belém-PA, Brasil. E-mail: kdgfernandes@ufpa.br
} 
Avaliação da distribuição de cobre associado a compostos de diferentes massas moleculares na polpa de açaí

\section{INTRODUÇÃO}

O açaí (Euterpe oleracea Mart.) ou juçara, como é conhecido em algumas regiôes amazônicas, é uma espécie nativa da Amazônia, encontrada em alguns países, como a Venezuela, Colômbia, Equador e Brasil (Alexandre et al. 2004). É comumente encontrado em áreas de terra firme, principalmente quando localizadas próximas às várzeas e aos igapós. Destaca-se entre os diversos recursos vegetais pela sua abundância e por produzir um importante alimento para as populaçóes locais, além de ser a principal fonte de matériaprima para a agroindústria de palmito no Brasil. $\mathrm{O}$ açaí é considerado um alimento de elevado valor calórico, com alto percentual de lipídeos, e nutricional, pois é rico em proteínas e minerais ( $\mathrm{Fe}, \mathrm{Cr}, \mathrm{Cu}$ etc). O suco do açaí conhecido pela população amazônica como "vinho" é utilizado na forma de sorvetes, cremes, iogurtes e licores (Sousa et al. 2006).

Os alimentos são as principais fontes de minerais para o organismo humano. Vários íons metálicos presentes nos alimentos são encontrados associados as proteínas específicas ou enzimas, como centros ativos ou estruturais e em processos de transporte e estocagem (Silva e Williams 2001; Lippard e Berg 1994).

Nos últimos anos, a Química Analítica tem se voltado não apenas à determinação de elementos-traço, mas também tem buscado através da especiação de elementos-traço informaçôes mais completas para identificar as formas químicas (espécies) e as estruturas dos compostos aos quais diferentes elementos estão associados. Além disto, busca-se quantificar individualmente uma ou mais espécies químicas (Sanz Medel 2005; Cornelis et al. 2003). Estudos envolvendo especiação química podem auxiliar na avaliação da biodisponibilidade destes elementos possibilitando a obtenção de novos dados para prever sua absorção.

O elemento cobre, por exemplo, está presente em algumas enzimas, tais como superóxido dismutase, lisil oxidase e citocromo oxidase, as quais possuem suas funcionalidades dependentes do cobre. Este elemento também promove a formação de glóbulos vermelhos normais, ajuda a converter o ferro à forma férrica e a transportá-lo dentro do organismo.

Alguns autores têm mostrado que determinados elementos presentes nas frutas estão principalmente associados às proteínas albuminas e globulinas (Araújo et al. 2004, Naozuka e Oliveira 2007).

Cromatografia a líquido de exclusão por tamanho (SEC) têm sido usada para estudar a distribuição dos elementos a diferentes grupos de substâncias presentes em determinada amostra (Ponce de Leon et al. 2002).

Técnicas seletivas e com adequada sensibilidade têm sido usadas para detecção de elementos em estudos de fracionamento, distribuição e especiação química (Gonçalves et al. 2009; Naozuka e Oliveira 2007; Kannamkumarath et al. 2002). A espectrometria de absorção atômica em forno de grafite (GF AAS) é uma técnica analítica bem estabelecida e suficientemente robusta para ser implantada em laboratórios envolvidos com rotina em larga escala (Welz 1999). A técnica GF AAS tem proporcionado desenvolvimentos e aplicaçôes relevantes em decorrência dos excelentes limites de detecção, pequenos volumes de amostra requeridos, possibilidade de análise direta, rapidez e seletividade (Butcher e Snnedon 1998). Contudo, o acoplamento on-line da cromatografia a líquido com detector GF AAS têm sido bastante limitado comparativamente às outras técnicas de espectrometria atômica. Isso pode ser compreendido pela relativa incompatibilidade entre o caráter de fluxo contínuo da técnica cromatográfica e o caráter em batelada da espectrometria atômica com atomização eletrotérmica. Assim, o procedimento para a determinação do elemento associado às espécies obtidas por SEC é baseado na coleta das fraçôes após separação cromatográfica implicando na posterior quantificação das fraçóes off-line por GF AAS (Soldado et al. 1997; Naozuka et al. 2010).

O presente trabalho tem como objetivo investigar a associação de cobre à compostos de alta e baixa massa molecular presentes na polpa de açaí por cromatografia de exclusão por tamanho (SEC) e espectrometria de absorçấo atômica em forno de grafite (GF AAS).

\section{MATERIAL E MÉTODOS}

Os frutos do açaí foram adquiridos no Mercado do Vêr-oPeso, na cidade de Belém (PA). Os frutos foram inicialmente secos em estufa à $35^{\circ} \mathrm{C}$ durante três dias até peso constante (Trindade 2010). Em seguida, a polpa e o caroço dos frutos foram separados. As polpas secas obtidas a partir de um pool de cerca de 100 frutos foram pulverizadas em gral de porcelana. A amostra pulverizada foi armazenada em um frasco de polietileno.

A digestáo da polpa de açaí foi realizada em triplicatas. Sub-amostras de aproximadamente 0,4 gramas foram pesadas e transferidas para tubos de digestão, sendo em seguida adicionados 1,0 $\mathrm{mL} \mathrm{HNO}_{3}$ concentrado $\left(14,0 \mathrm{~mol} \mathrm{~L}^{-1}\right)$. A mistura foi mantida em repouso por 12 horas. Antes dos tubos contendo a mistura serem colocados no bloco digestor foram adicionados $2,0 \mathrm{~mL} \mathrm{HNO}_{3}$ concentrado $\left(14 \mathrm{~mol} \mathrm{~L}^{-1}\right)$ e $1,0 \mathrm{~mL}$ de $\mathrm{H}_{2} \mathrm{O}_{2} 30 \%(\mathrm{~m} / \mathrm{m})$, e em seguida, as amostras foram colocadas no bloco digestor a temperatura de $130{ }^{\circ} \mathrm{C}$. Transcorridas três horas do início do processo de digestão, a temperatura foi elevada a $150{ }^{\circ} \mathrm{C}$. Verificado a diminuição da formação de gases após duas horas nesta temperatura e finalmente para garantir que toda gordura presente nas amostras fosse digerida, a temperatura foi elevada para $180^{\circ} \mathrm{C}$ e mantida durante uma hora (Trindade 2010). Os tubos de digestão foram retirados do bloco e resfriados a temperatura 
Avaliação da distribuição de cobre associado a compostos de diferentes massas moleculares na polpa de açaí ambiente. Após o resfriamento, os digeridos obtidos foram transferidos para frascos volumétricos e os volumes ajustados para $25 \mathrm{~mL}$ com água desionizada. $\mathrm{O}$ branco analítico foi preparado pelo mesmo procedimento sem a adição da amostra.

A remoçáo dos lipídeos da polpa de açaí foi realizada usando uma soluçáo extratora de clorofórmio $\left(\mathrm{CHCl}_{3}\right)$ e metanol $\left(\mathrm{CH}_{3} \mathrm{OH}\right)(2: 1 \mathrm{v} / \mathrm{v})$, segundo Kannamkumarath et al. (2002). Os sobrenadantes ricos em lipídeos (fração lipídica) foram descartados. O resíduo obtido foi seco em estufa à $30{ }^{\circ} \mathrm{C}$ por 20 minutos. $\mathrm{O}$ resíduo foi submetido a extração com solução de $\mathrm{NaOH}$.

A extração das proteínas com $\mathrm{NaOH} 0,05 \mathrm{~mol} \mathrm{~L}^{-1}$ foi realizada de acordo com o procedimento proposto por Kannamkumarath et al. (2005). Os precipitados (proteínas) obtidos foram solubilizados em $2,5 \mathrm{mmol} \mathrm{L}^{-1}$ de Tris$\mathrm{HCl}(\mathrm{pH}=7,4)$ contendo SDS $(0,5 \% \mathrm{~m} / \mathrm{v})$ e injetados no sistema cromatográfico. Esse procedimento foi repetido e os precipitados obtidos foram submetidos a digestão ácida para posterior determinaçáo de cobre total associado às proteínas.

A quantificação de proteínas na fração protéica da polpa de açaí foi realizada de acordo com o método proposto por Bradford (1976). Um espectrofotômetro marca CECIL (Modelo CE2041, Bulk Scientific, Inglaterra) foi empregado. $\mathrm{Na}$ calibração do método foi utilizada uma soluçâo estoque de albumina bovina. A equação da reta e o coeficiente de correlaçáo $(r)$ obtidos foram $\mathrm{y}=0,0012 \mathrm{x}+0,0135$ e 0,9979 , respectivamente.

O teor total de cobre nos digeridos de polpa de açaí $(n=3)$ e na fração extraída com solução de $\mathrm{NaOH}(n=3)$ foi determinado usando um espectrômetro de absorçáo atômica com chama (SPECTRA AA 220, Varian, Austrália).

A separação cromatográfica foi otimizada usando padróes de proteínas e um cromatógrafo a líquido de alta eficiência (ProStar 210, Varian, Austrália). As soluçôes padróes das proteínas $\left(2 \mathrm{mg} \mathrm{mL}^{-1}\right)$ foram preparadas através da dissoluçáo de massas adequadas de albumina $(67 \mathrm{kDa})$, mioglobina $(17 \mathrm{kDa})$ e seleno-metionina $(0,19 \mathrm{kDa})$ na fase móvel contendo $2,5 \mathrm{mmol} \mathrm{L}^{-1}$ de Tris- $\mathrm{HCl}(\mathrm{pH}=7,4) \mathrm{em}$ SDS $(0,5 \% \mathrm{~m} / \mathrm{v})$. Ferritina $\left(440 \mathrm{mg} \mathrm{mL}^{-1}\right)$ foi usada para obter o volume da coluna cromatográfica. As condiçôes cromatográficas otimizadas para a separaçáo dos padróes de proteínas por cromatografia de exclusão por tamanho (SEC) sáo apresentadas na Tabela 1.

$\mathrm{O}$ coeficiente de partição foi calculado usando $\mathrm{K}_{\mathrm{av}}=$ $\left(\mathrm{V}_{\mathrm{e}}-\mathrm{V}_{\mathrm{o}}\right) /\left(\mathrm{V}_{\text {total }}-\mathrm{V}_{\mathrm{o}}\right)$. O volume da coluna $\left(\mathrm{V}_{\mathrm{o}}\right)$ foi $5,92 \mathrm{~mL}$. A equação obtida na calibração da coluna cromatográfica $\left(\log \mathrm{MM}\right.$ versus $\left.\mathrm{K}_{\mathrm{av}}\right)$ foi $\log \mathrm{MM}=-4,3161 \mathrm{~K}_{\mathrm{av}}+4,7223$ $(r=0,9884)$, onde MM e $r$ são a massa molecular e o coeficiente de correlação, respectivamente.
Tabela 1 - Condições operacionais para cromatografia de exclusão por tamanho

\begin{tabular}{lc}
\hline Coluna & Biosep - SEC - S $3000(300 \mathrm{~mm} \times 7.8 \mathrm{~mm})$ \\
\hline Alça de amostra $(\mathrm{mL})$ & 20 \\
Vazão do eluente $(\mathrm{mL} \mathrm{min}-1)$ & 0,6 \\
Eluente & $2,5 \mathrm{mmol} \mathrm{L}^{-1}$ Tris- $\mathrm{HCl}(\mathrm{pH}=7,4)$ em SDS \\
Detecção das proteínas & $(0,5 \% \mathrm{~m} / \mathrm{v})$ \\
\hline
\end{tabular}

A fraçáo obtida a partir da extraçáo com soluçáo de $\mathrm{NaOH}$ da polpa de açaí foi solubilizada com $500 \mathrm{~mL}$ de $2,5 \mathrm{mmol}$ $\mathrm{L}^{-1}$ Tris- $\mathrm{HCl}(\mathrm{pH}=7,4)$ em SDS $(0,5 \% \mathrm{~m} / \mathrm{v})$ e em seguida injetada no sistema SEC-UV. O cromatograma dos compostos presentes na polpa de açaí foi registrado. Novamente, a amostra foi injetada no sistema cromatográfico e desta vez, as fraçôes obtidas durante a separação cromatográfica foram coletadas de um em um minutos e em seguida foram liofilizadas. Após a liofilização, as fraçôes foram solubilizadas em $\mathrm{HNO}_{3}(0,028$ mol L-1) e a concentraçấo de cobre nas fraçôes foi determinada usando um espectrômetro de absorçáo atômica em forno de grafite (SPECTRAA 220, Varian, Austrália). As condiçóes instrumentais para determinaçáo de cobre por GF AAS são apresentadas na Tabela 2.

A exatidáo do procedimento proposto em GF AAS foi avaliada usando o método de adição e recuperaçáo de 5,0 $\mu \mathrm{g}$ $\mathrm{L}^{-1} \mathrm{Cu}$ nas frações coletadas do sistema cromatográfico.

Tabela 2 - Programa de aquecimento do forno de grafite

\begin{tabular}{ccccc}
\hline Etapa & Temperatura $\left({ }^{\circ} \mathrm{C}\right)$ & $\begin{array}{c}\text { Tempo }(\mathrm{s}) \\
(\text { rampa, patamar) }\end{array}$ & $\begin{array}{c}\text { Vazão do gás de } \\
\text { purga }(\mathrm{L} / \mathrm{min})\end{array}$ & Leitura \\
\hline 1 & 95 & 5,40 & 3,0 & Não \\
2 & 120 & 10,30 & 3,0 & Não \\
3 & $1000\left(\mathrm{~T}_{\mathrm{p}}\right)$ & 5,20 & 3,0 & Não \\
4 & $2300\left(\mathrm{~T}_{\mathrm{a}}\right)$ & 2,0 & 0 & Sim \\
5 & 2400 & 1,3 & 3,0 & Não \\
\hline
\end{tabular}

$\mathrm{T}_{\mathrm{p}}$ : Temperatura de pirólise; $\mathrm{T}_{\mathrm{a}}$ : Temperatura de atomização.

\section{RESULTADOS E DISCUSSÃO}

\section{Avaliação da concentração total de cobre}

A concentração de cobre obtida na polpa de açaí estudada foi $10,5 \pm 0,2 \mu \mathrm{g} \mathrm{g}^{-1}$ ou $1,05 \mathrm{mg} 100 \mathrm{~g}^{-1}$. Este valor encontrado

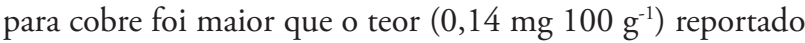
na tabela brasileira de composiçáo de alimentos (TACO) para amostra de açaí. O nível de cobre $\left(21,3 \mu \mathrm{g} \mathrm{g}^{-1}\right)$ encontrado por Dolan e Capar (2002) foi maior quando comparado ao valor obtido neste estudo. Esta variaçấo na concentração do mineral pode estar relacionada com a origem geográfica, o uso de fertilizantes, as condições climáticas e do solo e as 
Avaliação da distribuição de cobre associado a compostos de diferentes massas moleculares na polpa de açaí características das plantas que podem alterar a concentração dos elementos nos alimentos (Dolan e Capar 2002; Ibañez e Cifuentes 2001).

O consumo diário recomendado de cobre pela Organização Mundial de Saúde (OMS) é de 5,0 mg para uma pessoa de 60 $\mathrm{kg}$. Sendo assim, podemos dizer que o teor de cobre encontrado na polpa de açaí estudada pode contribuir com 21,0\% dos valores diários recomendados para a dieta alimentar de um homem adulto. Logo, a polpa de açaí pode ser considerada como uma potencial fonte de cobre para humanos.

A exatidão do procedimento proposto foi avaliada usando o método de adição e recuperação de $0,5 \mathrm{mg} \mathrm{L}^{-1} \mathrm{Cu}$ nos digeridos de polpa de açaí. Os resultados de recuperaçáo obtidos no digerido da polpa de açaí por FAAS para cobre foram $98 \%$ a $102 \%$, respectivamente. Os desvios padrão obtidos foram $<2,0 \%$. Os limites de detecção $(3 \times \mathrm{s} / \mathrm{b})$ e quantificação $(10 \mathrm{x} \mathrm{s} / \mathrm{b}$; s= desvio padrão do branco analítico; $\mathrm{b}=$ coeficiente linear do gráfico de calibração) obtidos para cobre por FAAS foram 0,63 e 2,5 $\mu \mathrm{g} \mathrm{g}^{-1}$, respectivamente.

\section{Determinação do teor de proteína total}

A concentração de proteínas totais obtida na fração protéica extraída com $\mathrm{NaOH}$ foi $6,88 \pm 0,09 \mathrm{mg} \mathrm{g}^{-1}$. Segundo (Cantarow e Schepartz 1969), as proteínas glutelinas (proteínas simples) podem ser extraídas com soluçáo de ácido ou base diluída, pois são insolúveis em água pura e em soluçôes diluídas de sais. A solubilidade de uma proteína depende da composição de aminoácidos básicos e ácidos e de suas partes não protéicas (Sgarbieri 1996). De acordo com Wuilloud et al. (2004), a solução de $\mathrm{NaOH}$ pode extrair espécies de alta (HMW) e baixa massa molecular (LMW). Entretanto, a solução de $\mathrm{NaOH}$ não é um agente extrator seletivo de proteínas (Chunhieng et al. 2004; Kwon et al. 1996). Por isso, a etapa de purificação das proteínas é de suma importância para sua identificação e caracterização, pois pode evitar que outros compostos estejam presentes na fração protéica além de proteínas. Sendo assim, podemos supor que outras proteínas simples, tais como albuminas, prolaminas e entre outras podem estar presentes nesta fração, e então não sendo constituída apenas por proteínas do grupo das glutelínas.

\section{Separação cromatográfica das proteínas por SEC-UV}

A fim de otimizar a separação das proteínas foram estudados o melhor tempo de eluição, comprimento de onda, concentração da fase móvel e a vazão da fase móvel. As melhores condiçóes cromatográficas foram obtidas para uma eluição isocrática de $2,5 \mathrm{mmol} \mathrm{L}^{-1}$ Tris- $\mathrm{HCl}(\mathrm{pH}=7,4)$ em SDS $(0,5 \% \mathrm{~m} / \mathrm{v}$ ) durante $30 \mathrm{~min}$ (Tabela 2) usando o comprimento de onda de $295 \mathrm{~nm}$. A relação entre o volume de eluição $\left(\mathrm{V}_{\mathrm{e}}\right)$ e o logaritmo da massa molecular foi linear na razão entre 0,196 a $67 \mathrm{kDa}$. Os coeficientes de partição $\left(\mathrm{K}_{\mathrm{av}}\right)$ obtidos durante a calibração da coluna foram 0,008 (albumina), 0,079 (mioglobina) e 0,568 (seleno-metionina) usando uma soluçáo de $2,5 \mathrm{mmol} \mathrm{L}^{-1}$ Tris- $\mathrm{HCl}(\mathrm{pH}=7,4)$ em SDS $(0,5 \%$ $\mathrm{m} / \mathrm{v}$ ) durante $30 \mathrm{~min}$. Antes da separação cromatográfica de cada padrão ou amostra, um branco analítico foi injetado a fim de controlar a limpeza do sistema cromatográfico. O perfil cromatográfico para a extração básica $(\mathrm{NaOH})$ com detecção UV à 295 nm é mostrado na Figura 1 .

Como pode ser visto, o perfil cromatográfico obtido no extrato básico da polpa de açaí mostrou a presença de compostos de HMW (28,7 kDa) e LMW (2,6 e 0,43 $\mathrm{kDa})$. Os coeficientes de partição obtidos para as massas moleculares de $28,7,2,6$ e $0,43 \mathrm{kDa}$ foram 0,061, 0,300 e 0,484 , respectivamente. Como era esperado, a solução de $\mathrm{NaOH}$ 0,05 mol L-1 extraiu compostos de HMW e LMW (Wuilloud et al. 2004). A massa molecular de 28,7 kDa pode ser proteínas devido as suas altas quantidades em alimentos. Por outro lado, as espécies de LMW encontradas podem ser peptídeos contendo metal ou outros compostos de LMW que foram extraídos com a solução de $\mathrm{NaOH}$.

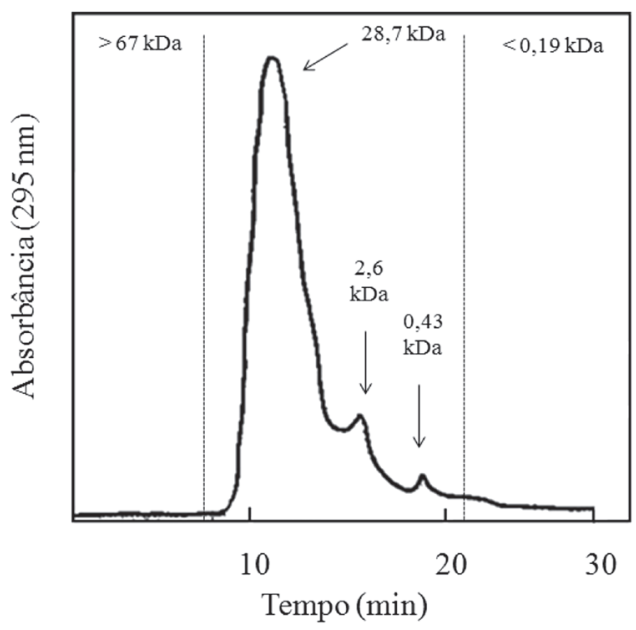

Figura 1 - Perfil cromatográfico obtido após extração da polpa de açaí com solução de NaOH 0,05 mol L-1 por SEC com detecção UV a $295 \mathrm{~nm}$.

\section{Determinação de cobre nas frações por GF AAS}

Cobre foi determinado nas frações $(n=30)$ obtidas por SEC-UV. O nível de cobre no solvente da fase móvel estava abaixo do limite de detecção $\left(<0,7 \mathrm{ng} \mathrm{g}^{-1}\right)$. Os teores de cobre obtidos em cada fração são mostrados na Figura 2.

Cobre foi encontrado associado às espécies de $28,7 \mathrm{kDa}$, 2,6 kDa e $0,43 \mathrm{kDa}$ no extrato de $\mathrm{NaOH}$ da polpa de açaí. Os níveis mais elevados de cobre foram encontrados associados as massas moleculares de $28,7 \mathrm{kDa}(43,8 \%$ da soma total de cobre nas fraçóes) e $2,6 \mathrm{kDa}(41,5 \%)$. 


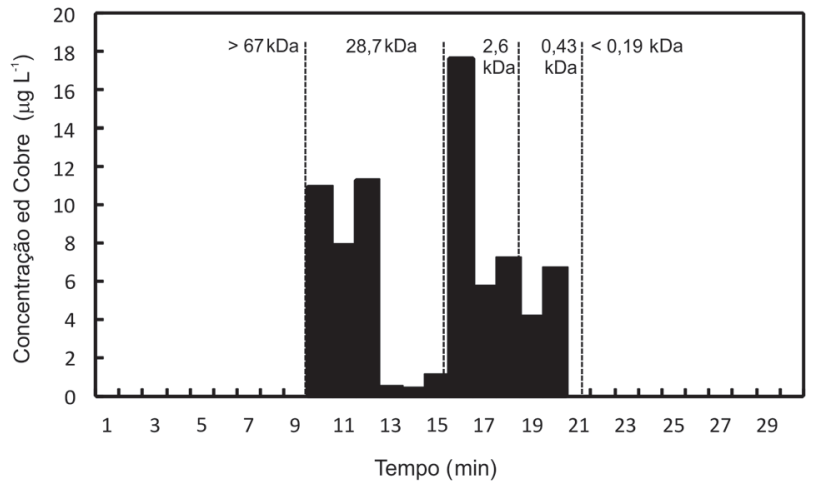

Figura 2 - Níveis de cobre $\left(\mu \mathrm{g} \mathrm{L}^{-1}\right)$ associados a compostos de HMW e LMW presentes na extração básica da polpa de açaí.

Uma recente publicação demonstrou a presença de cobre associado à compostos de HMW (13,0 a 3,3 kDa) e LMW (1,3 kDa) em alimentos (Wuilloud et al. 2004).

Os limites de detecção e quantificaçáo obtidos para cobre por GF AAS foram 0,7 e 2,2 $\mathrm{ng} \mathrm{g}^{-1}$, respectivamente.

\section{CONCLUSÃO}

Com bases nos resultados obtidos podemos dizer que a polpa de açaí possui uma grande potencialidade como fonte de cobre para seres humanos. $\mathrm{O}$ teor de cobre encontrado pode contribuir para a dieta alimentar. A extração sólido-líquido combinada com FAAS foi eficiente para a determinação de cobre na fraçáo básica da polpa de açaí obtida com o agente extrator $\mathrm{NaOH}$. Além da quantificação de cobre na polpa de açaí por FAAS foi possível a detecçâo de compostos de alta e baixa massa molecular associados ao cobre por SEC-GF AAS. Os resultados obtidos mostraram que cobre está associado a compostos de HMW e LMW na polpa de açaí.

\section{AGRADECIMENTOS}

Os autores agradecem à Fundaçáo de Apoio a Pesquisa do Estado do Pará (FAPESPA) pelo apoio financeiro (Projeto PPP FAPESPA 024/2008) e bolsa de Samantha L. da Trindade e também ao Conselho Nacional de Desenvolvimento Científico e Tecnológico (CNPq) pelas bolsas de Kelly das Graças Fernandes (Proc. 305790/2008-0) e Patrícia de Oliveira Nunes (Proc. 551983/2009-4).

\section{BIBLIOGRAFIA CITADA}

Alexandre, D.; Cunha, L.R.; Hubinger, D.M. 2004. Preservation of the assai pulp through the application of obstacles. Ciência e Tecnologia de Alimentos, 24:114-119 (in Portuguese with abstract in English).

Araújo, C.L.; Bezerra, I.W.L.; Dantas, I.C.; Lima, T.V.S.; Oliveira, A.S.; Miranda, M.R.A.; Leite, E.L.; Sales, M.P. 2004. Biological activity of proteins from pulps of tropical fruits. Food Chemistry, $85: 107-110$

Bradford, M.M. 1976. A Rapid and Sensitive Method for the Quantitation of Microgram Quantities of Protein Utilizing the Principle of Protein-Dye Binding. Analytical and Biochemistry, 72: 248-254.

Butcher, D.J.; Sneddon, J. 1998. A pratical guide to graphite furnace atomic absorption spectrometry. New York: John Wiley \& Sons. $250 \mathrm{pp}$

Cantarow, A.; Schepartz, B. 1969. Biochemistry. 4ª Ed., Atheneus S. A. Rio de Janeiro.920pp (in Portuguese)

Chunhieng, T.; Pétritis, K.; Elfakir, C.; Brochier, J.; Goli, T.; Montet, D. 2004. Study of Selenium Distribution in the Protein Fractions of the Brazil Nut, Bertholletia excelsa. Journal of Agricultural and Food Chemistry, 52: 4318-4322.

Cornelis, R.; Caruso, J.; Crews, H.; Heumann, K. 2003. Handbook of elementalspeciation: techniques and methodology. New Jersey: John Wiley \& Sons.656pp.

Dolan, S.P.; Capar, S.G. 2002. Multi-element analysis of food by microwave digestion and inductively coupled plasma-atomic emission spectrometry. Journal of Food Composition and Analysis, 15: 593-615.

Garcia, J.S.; Magalhães, C.S.; Arruda, M.A.Z. 2006. Trends in metal-binding and metalloprotein analysis. Talanta, 69: 1-15.

Gonçalves, A.M.; Fernandes, K.G.; Ramos, L. A.; Cavalheiro, E.T.G.; Nóbrega, J.A. (2009). Determination and Fractionation of Barium in Brazil Nuts. Journal of the Brazilian Chemical Society, 20: 760-769.

Ibañez, E.;Cifuentes, A. 2001. New Analytical Techniques in food science. Critical Reviews in Food Science and Nutrition, 41: 413-450

Kannankumarath, S.S.; Wrobel, K.; Wuilloud, R.G. 2005. Studying the distribution pattern of selenium in nut proteins with information obtained from SEC-UV-ICP-MS and CE-ICP-MS. Talanta 66: 153-159.

Kannamkumarath, S.S.; Wrobel, K.; Wrobel, K.; Vonderheide, A.; Caruso, J.A. 2002. HPLC-ICP-MS determination of selenium distribution and speciation in different types of nut. Analytical and Bioanalytical Chemistry, 373: 454-460.

Kwon, K.; Park, K.H.; Rhee, K.C. 1996. Fractionation and characterization of Proteins from Coconut (Cocos nucifera L.). Journal of Agricultural and Food Chemistry, 44: 1471-1745.

Lippard, S.J., Berg, J.M. (1994) Principles of bioinorganic chemistry .University Science Books, Mill Valley, California, USA. 411pp

Naozuka, J; Oliveira, P.V. 2007. Cu, Fe, Mn and Zn distribution in protein fractions of Brazil-nut, cupuassu seed and coconut pulp by solid-liquid extraction and electrothermal atomic absorption spectrometry. Journal of the Brazilian Chemical Society, 18(8): 1547-1553.

Naozuka, J; Marana, S.R., Oliveira, P.V. 2010. Water-soluble Cu, Fe, $\mathrm{Mn}$ and $\mathrm{Zn}$ species in nuts and seeds. Journal of food composition and analysis, 23: 78-85. 
Avaliação da distribuição de cobre associado a compostos de diferentes massas moleculares na polpa de açaí
Ponce de Leon, C.A.; Montes-Bayón, M.; Caruso, J.A. 2002. Elemental speciation by chromatographic separation with inductively coupled plasma mass spectrometry detection. Journal of Chromatography A, 974:1.

Sanz-Medel, A. 2005. From metalloproteomics to heteroatom-tagged proteomics. Analytical and Bioanalytical Chemistry, 381: 1-2.

Silva, J.J.R.F.; Williams, R.J.P. 2001. The biological chemistry of the elements-The inorganic chemistry of life. 2a Ed.Oxford University Press, New York, USA. 575pp.

Sousa, M.A.C.; Yuyama, L.K.O.; Aguiar, J.P.L.; Pantoja, L. 2006. Acai Juice: microbiological, heat treatment and shelf life. Acta Amazonica, 36: 483-496 (Portuguese with abstract in English).

Sgarbieri, V.C. 1996. Proteins in food: properties - degradation - changes. São Paulo: Livraria Varella. 520pp (in Portuguese)
Soldado, A.B.; Blanco González, E.; Sanz Medel, A. 1997. Quantitative Studies of aluminium binding species in human uremic serum by Fast protein liquid chromatography coupled with electrothermal atomic absorption spectrometry, Analyst, 122: 573-577.

Trindade, S. L. 2010. Determination and fractionation of trace elements in regional fruits. Dissertação de mestrado, Universidade Federal do Pará, Belém, Pará.74pp (in Portuguese)

Welz, B., Sperling, M.(1999) Atomic absorption spectrometry. 3 ed. Weinheim:Wiley-VCH. 941pp

Wuilloud, R.G.; Kannamkumarath S.S.; Caruso J.A. 2004. Speciation of nickel, copper, zinc, and manganese in different edible nuts: a comparative study of molecular size distribution by SEC-UV-ICP-MS. Analytical and Bioanalytical Chemistry, 3: 495-503.

Recebido em 15/11/2010

Aceito em 09/04/2011 